\title{
RECENTE AANWINSTEN VAN DE AFDELING AZIATISCHE KUNST
}

\section{- Een fichesdoos}

Het Rijksmuseum коснт het afgelopen jaar een doos voor kaarten en fiches van Chinees lakwerk (afb. 1). De doos is een voorbeeld van de beste kwaliteit exportlak uit de periode $1840-1850$ en is uitstekend bewaard gebleven.

De buitenkant is naar de mode van de tijd vol gedecoreerd met bladmotieven en kostbare voorwerpen die in licht reliëf in goud zijn aangebracht op een zwarte ondergrond. Het goud is aangebracht over een rode laklaag die op sommige plaatsen zichtbaar is waar het goud gesleten is. De cartouches zijn geheel gevuld met een groot aantal Chinezen in landschapjes. Alles is even nauwkeurig geschilderd. Aan de binnenzijde bevinden zich de dozen voor kaarten en fiches en de schaaltjes voor de fiches (afb. 2). De kaarten ontbreken helaas, maar de fiches zijn bewaard.

EXPORTLAKWERK UIT DE 18e en 19e eeuw staat niet bekend om zijn hoge kwaliteit. Om een goed resultaat te bereiken is veel tijd nodig, want juist vele dunne lagen, die alle hun tijd nodig hebben om uit te harden, zorgen voor een hard, glad en glanzend oppervlak. De Chinese lakwerkers probeerden zich er meestal met een paar lagen vanaf te maken. Omdat lak, het sap van de boom Rhus Vernicifera, duur is, gebruikten ze het dikwijls niet in zuivere vorm, maar werd het - zeker in de grondlagen - aangelengd met andere, goedkopere stoffen. Het resultaat is een kwetsbaarder product dat niet zo goed zijn glans weet te behouden. Als argument is wel aangevoerd dat de lakwerkers maar weinig tijd hadden voor de vervaardiging van hun producten. De Westerse handelaren verbleven elk jaar maar relatief korte tijd in Kanton en in die tijd moesten alle bestellingen vervaardigd zijn. Het is maar de vraag of dat werkelijk de verklaring is. Fichesdozen zoals deze behoren vanaf de $18 \mathrm{e}$ eeuw tot het standaardrepertoire aan souvenirartikelen die door westerlingen uit China werden meegenomen. Er bestond dus een markt voor en de stukken werden niet op bestelling gemaakt maar er werd een voorraad voor de markt vervaardigd.

IN DE PERIODE waarin de fichesdoos van het Rijksmuseum is gemaakt, waren niet langer de Europeanen de belangrijkste kopers van Chinese goederen in Kanton, maar de Amerikanen. De Amerikanen namen de smaak van hun voorgangers naadloos over. Van de kapitein van het eerste Amerikaanse schip dat in 1785 handel dreef in Kanton, de Empress of China, is bekend wat hij voor eigen gebruik kocht. Als vanzelfsprekend waren daar lakwerken fichesdozen bij, maar liefst 14 stuks. Fichesdozen zijn de gehele eerste helft van de $19 \mathrm{e}$ eeuw in de mode gebleven.

Zoals gezegd onderscheidt de aanwinst van het Rijksmuseum zich in kwaliteit van het schilderwerk en in duurzaamheid. Dat het in dit geval niet 


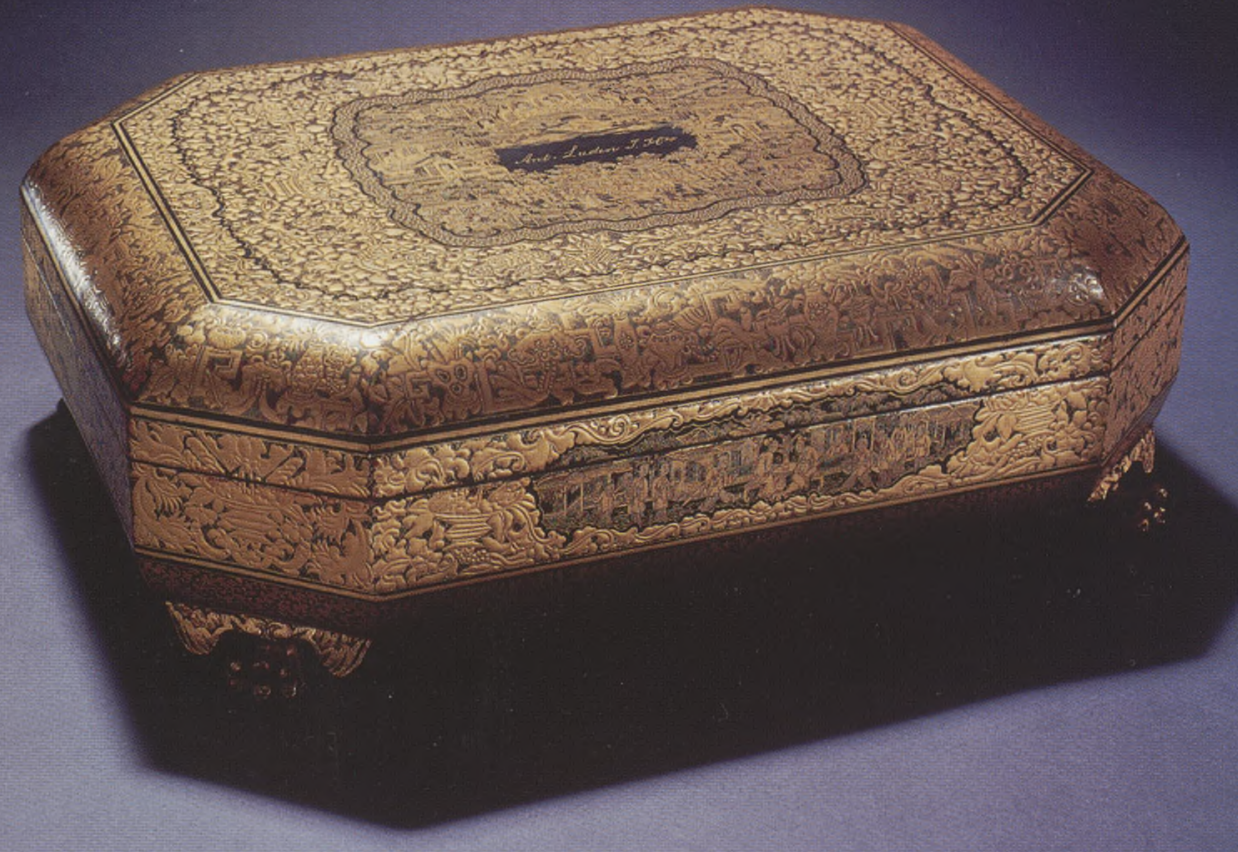

Afbeelding 1 (boven)

Fichesdoos met

7 binnendoosjes,

12 fichesschoteltjes en

126 parelmoeren fiches

Hout met zwarte lak en goudlak

China, ca. 1845

h. $11,4 \mathrm{~cm}$., l. $37,5 \mathrm{~cm}$.,

b. $29,5 \mathrm{~cm}$.

Op de buitenzijde van de deksel: 'Ant: Luden J.

Hzn'; op de binnenzijde van de deksel: 'souvenir de R.R. toe Laer' inv.nr. AK-RAK-2002-3 Aankoop bij kunsthandel J. Polak, Amsterdam

\section{Afbeelding 2}

Fichesdoos, binnenkant

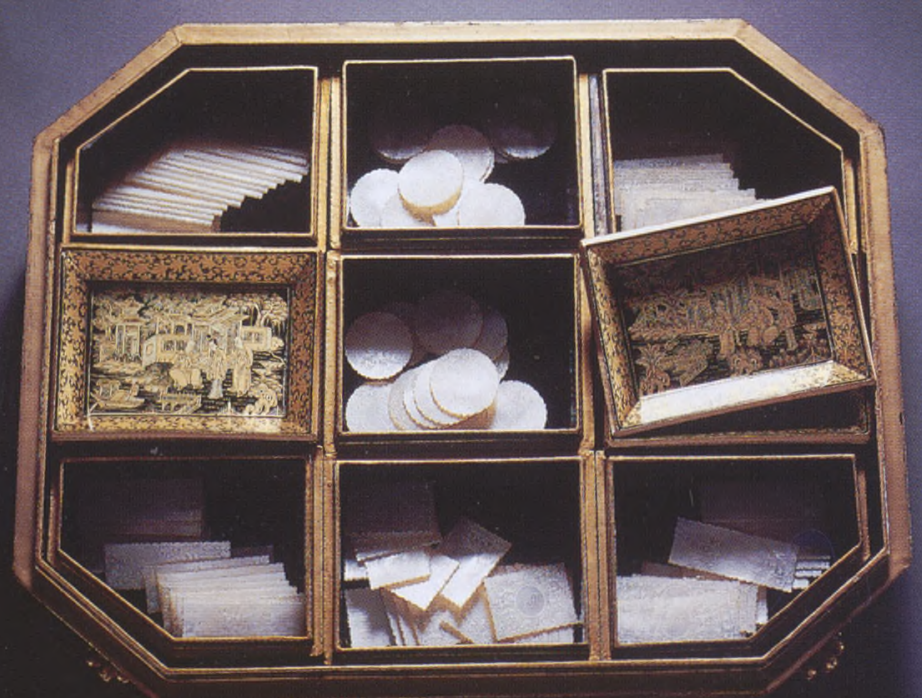


geheel een confectie-product betreft, maar een ten dele op maat gemaakte doos is, blijkt wel uit de inscripties die op de deksel en de fiches zijn aangebracht. Op de buitenzijde van de deksel staat 'Ant: Luden J. Hzn', en op de binnenzijde 'souvenir de R.R. toe Laer'. Met Ant: Luden moet Anthony Luden zijn bedoeld die leefde van 1794 tot 1846 en wiens vader Herman heette. Hij trouwde in 1819 met Hermanna Aleida toe Laer (1799-1854). Gezien de inscriptie 'souvenir de R.R. toe Laer' is het waarschijnlijk dat de doos een geschenk is geweest van een jongere broer van Hermanna, Robbert Reinard toe Laer (1814-1866). Deze Robbert Reinard was koopman en assuradeur en moet tenminste een deel van zijn leven in Azië hebben doorgebracht, want in 1839 is hij in Batavia getrouwd. Hoewel op de doos zelf alleen de naam van Anthony Luden is geschreven, dragen de fiches de inscripties ' $\mathrm{L}$ tL', hetgeen duidt op een herinnering aan de verbintenis van de beide families, meer in het bijzonder die van Anthony en Hermanna. Het huwelijk in 1819 ligt niet voor de hand, want de stijl van de doos komt niet overeen met de producten uit die tijd. Het is waarschijnlijker dat de doos een geschenk is geweest ter gelegenheid van een huwelijksjubileum. Aangezien dit zeker een kostbaar stuk moet zijn geweest, ligt de zilveren bruiloft in 1844 het meest voor de hand; dit komt uitstekend overeen met de stijl van de decoraties. Als Robbert Reinard vijf jaar na zijn huwelijk nog in Batavia woonde, heeft hij de doos waarschijnlijk in Batavia besteld bij een Chinese winkel waar hij soortgelijke dozen (maar zonder inscriptie) kon vinden. De Chinese handelaren in Batavia beschikten over uitstekende contacten met Chinezen in China. Aan de doos zelf hoefde alleen nog de namen worden toegevoegd, de fiches zullen speciaal voor de gelegenheid gesneden zijn. Prêt d porter dus.

\footnotetext{
Afbeelding 3 (pag. 13) Wachterfiguur (detail) China, eerste helft Se eeuw Aardewerk met glazuur h. 85 cm.

Legaat A. van Rossum inv.nr. AK-MAK-1717
}

\section{- Twee wachterfiguren}

DE KLEDING VAN deze twee wachterfiguren is in reliëf uitgewerkt en versierd met de drie kleuren van het sancai-glazuur (afb. 3). ${ }^{1}$ De lichamen zijn grotendeels identiek en zullen in dezelfde mal gemaakt zijn. Alleen de hoofden zijn individueel vormgegeven: een draagt een helm, terwijl de ander het haar in een knot heeft. De verfijnde gezichten zijn ongeglazuurd gebleven en dragen nog de resten van de oorspronkelijke beschildering, die de beelden een realistisch uiterlijk moest geven.

IN DE TANG-PERIODE (618-906) kreeg de bovenlaag van de Chinese bevolking een groep van zes figuren in het graf mee: twee hoogwaardigheidsbekleders, twee fantasiewezens, ter afschrikking van kwade geesten en twee van dergelijke wachterfiguren. De figuren werden aan weerszijden van de toegangsweg tot het graf opgesteld bij de aankomst van de begrafenisstoet, alvorens in het graf geplaatst te worden. Het formaat en de al maar rijkere versiering benadrukten de sociale status van de overledene. De productie vond plaats rond de hoofdstad Chang'an, waar het bloeiende hof en haar entourage voor een grote afzetmarkt zorg droeg. Dit type figuur werd gemaakt in de eerste helft van de achtste eeuw, tot een rebellie in het midden van de eeuw een einde maakte aan de productie. 


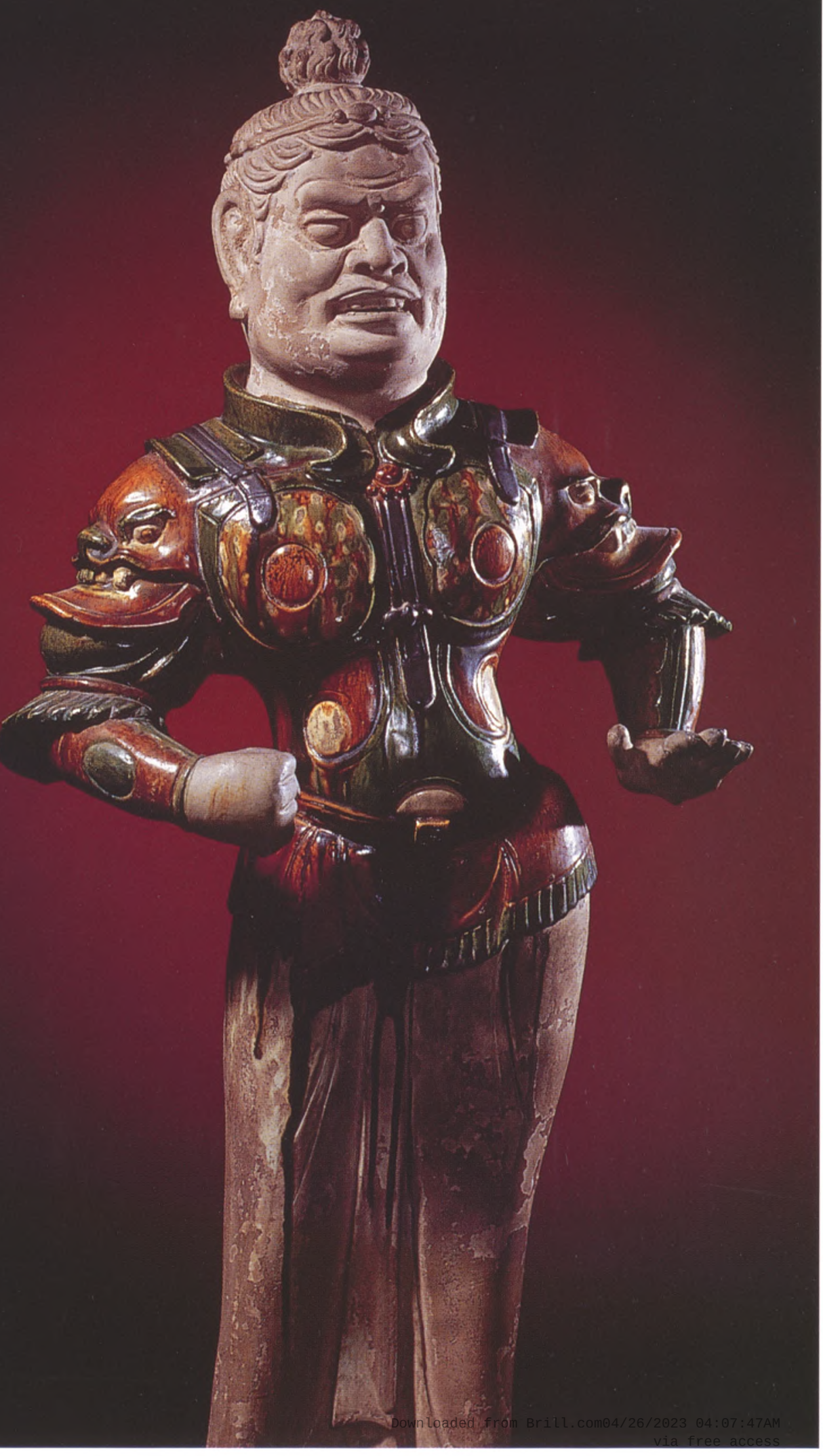




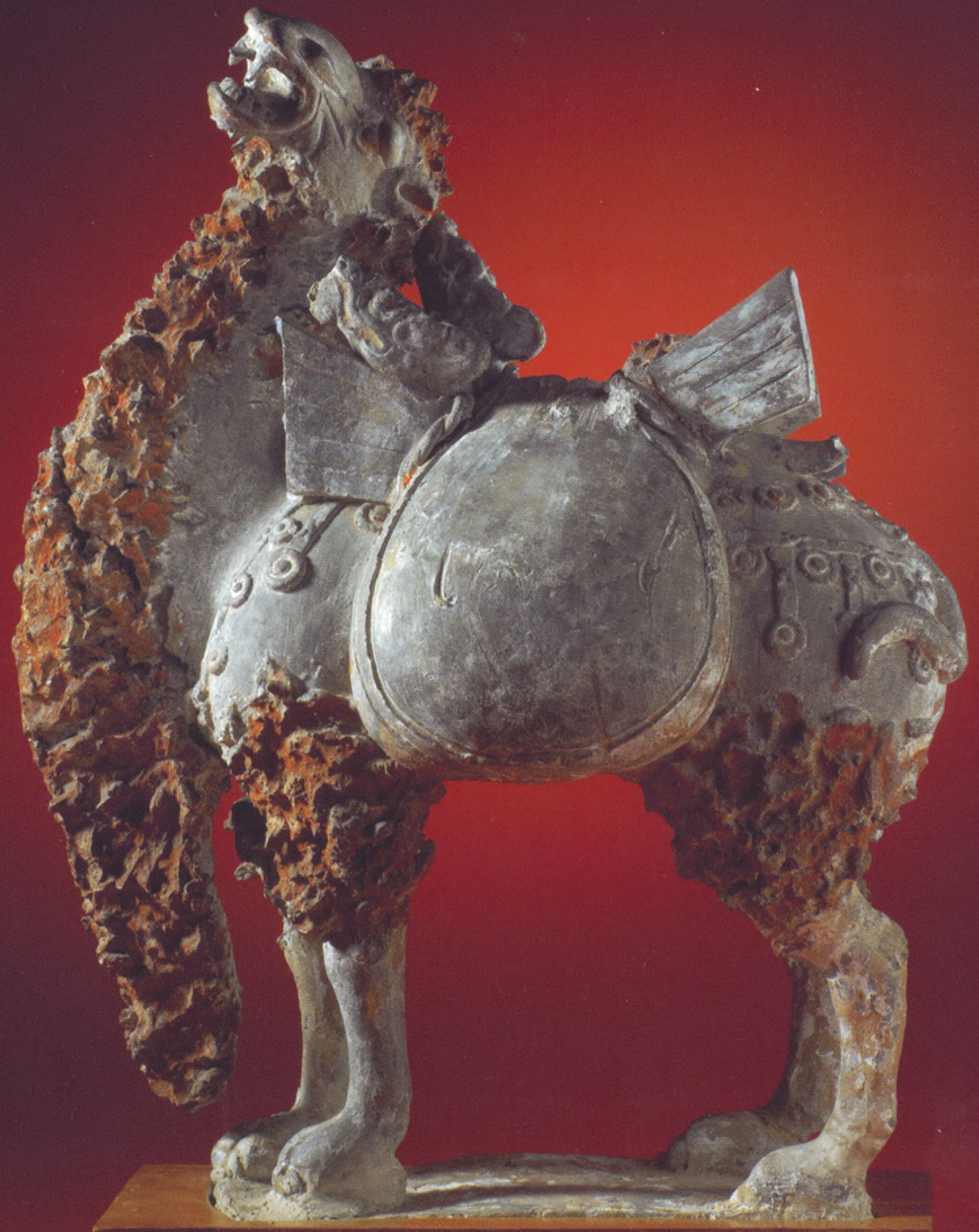


Afbeelding 4 (pag. 14) China, Noordelijke Wei-dynastie (386-535) Aardewerk met koude beschildering h. $36 \mathrm{~cm}$. Legaat A. van Rossum inv.nr. ak-mak-1718
KLEIFIGUREN VAN KAMELEN kwamen voor het eerst voor in de Han-periode (206 v. Chr.-220 n. Chr.). Later werden ze, net als hier (afb. 4), ook gezadeld en met hun last afgebeeld. In de late vierde eeuw verstevigde een platte, rechthoekige basis de benen, die eerst nog als rechte stokken werden weergegeven, maar bij deze figuur al met meer realistisch uiterlijk. Het lichaam is nog wel vrij stevig en gezet; in de latere eeuwen zou er meer beweging en sierlijkheid in de houding komen.

DEZE DIERFIGUREN GEVEN het gebruik van pakdieren aan voor de handel van China via de zijderoute met West-Azië. De uit Centraal-Azië afkomstige Wei-dynastie, die in de vijfde eeuw het Noorden van China verenigde, had van oorsprong natuurlijk een sterke band met het Aziatisch achterland. De invloed uit het Sassanidische Perzië is dan ook te zien in het versierde tuig, met de neerhangende medaillon-ornamenten.

\section{- Zeearend op een rots aan de kust}

Twee Japanse kamerschermen van

Kishi Ryo (Ganryo) (1798-1852)

OVER DE BREEDTE van twee kamerschermen (afb. 5) ontvouwt zich een gezicht met een zeearend op een rots aan de zeekust. Zijn krachtige gestalte domineert het rechterscherm, contrasterend met het lege zeegezicht op de linkerafbeelding. De vogel benadrukt nog eens de kijkrichting, die bij Japanse kamerschermen van rechts naar links is.

DEZE VERWERVING KON worden gedaan met gelden uit het legaat dat A. van Rossum naliet aan de Vereniging van Vrienden der Aziatische Kunst. De collectie van deze vereniging, die in permanente bruikleen is bij de afdeling Aziatische Kunst van het Rijksmuseum, beoogt een representatief overzicht te geven van hoogtepunten van de kunst uit Azië.

Dit paar kamerschermen past uitstekend in dit streven; uitbreiding van de van oorsprong beperkte collectie Japanse schilderkunst is een van de doelstellingen van het verzamelbeleid van de afdeling Aziatische Kunst. In de afgelopen jaren is zijn met name van schilders uit de naturalistische school een aantal kernstukken verworven. Deze stroming ontstond in het midden van de $18 \mathrm{e}$ eeuw en wordt ook wel de 'terugkeer naar de natuur' genoemd. Maruyama Okyo (1733-1795) wendde toen de al bestaande schildertechnieken aan op een nieuwe manier, om tot een meer realistische verbeelding te komen. Hij gaf bijvoorbeeld vormen volume door de punt van het met water gevulde penseel in inkt te dopen en met één streek een subtiele overgang van licht naar donker neer te zetten. Deze techniek (tsuketate) is op de kamerschermen van Ganryo te zien in bijvoorbeeld de weergave van de snavel van de arend. Een tweede kenmerk is de ruimtelijkheid van de voorstelling als geheel. Okyo kwam al op jeugdige leeftijd in aanraking met megane-e, optica-prenten die gebruikmaakten van het verdwijnpunt uit de Westerse schilderkunst om met spiegels en vergrootglazen een driedimensionale voorstelling te creëren. Ook een latere schilder uit de naturalistische school als Ganryo streefde naar dieptewerking, hier goed zichtbaar in het linkerscherm, waar rijen golven in de verte verdwijnen. $04: 07: 47 \mathrm{Am}$ 


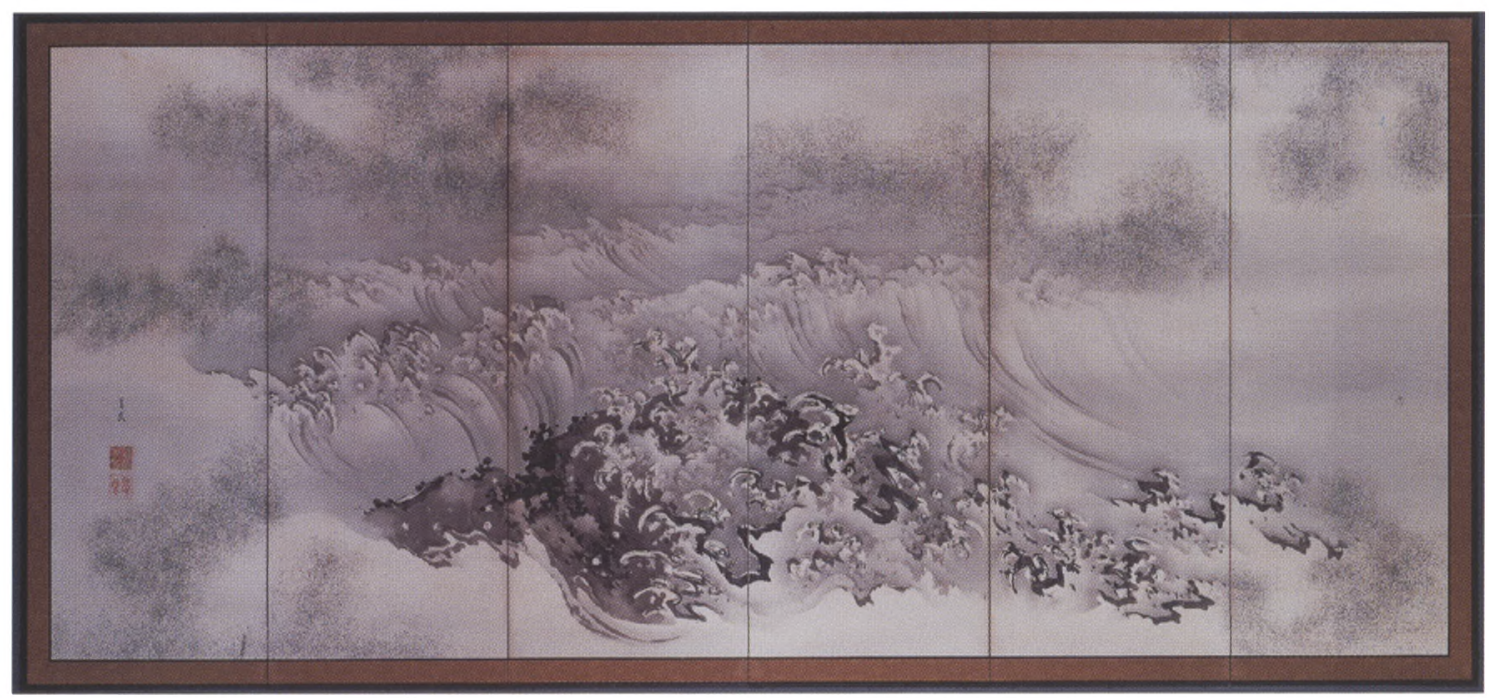

Afteelding 5

Zeearend op een rots aan de kust

Twee kamerschermen, inkt en kleur op papier Japan, ca. 1830-1840 $317,5 \times 171 \mathrm{~cm} .(2 \times)$ inv.nr. AK-MAK-1721 a, b

Aangekocht met gelden uit het legaat A. van Rossum, Maarssen
Het Rijksmuseum verwierf twee jaar geleden al een werk van Maruyama Okyo, tenslotte de oprichter van de beweging. Van Kishi Ganku (1749-1838), de grondlegger van de uit de Maruyama-school van Okyo voortkomende Kishi-school, werd al een drietal schilderingen aan de collectie toegevoegd. Ganryo was een neef van Ganku en werd later als leerling door hem geadopteerd. Hij zette de lijn van de Kishi-school voort, met de voor de school kenmerkende penseelvoering. Die bewegelijke en haast nerveuze schilderstijl is hier goed te zien bij de koppen van de golven, die als drakenklauwen uit het water lijken te komen. Het toont het streven van de Kishi-schilders naar een levendige vorm van realisme, waarbij ze niet volstonden met de werkelijkheid te kopiëren, maar vooral trachtten de essentie van het geschilderde onderwerp aan de toeschouwer over te brengen. Desalniettemin is de roofvogel goed te identificeren aan de grote snavel en de verentekening: het is een Steller zeearend (Haliaeetus pelagicus), een vaste bewoner van het uiterste noorden van Japan en een zeldzame winterbezoeker elders. Ganryo heeft de imponerende gestalte van de vogel, met een vleugelwijdte van meer dan twee meter, verbeeld op het moment dat hij zijn linkervleugel en -poot lijkt uit te strekken.

GANRYO WAS WERKZAAM in Kyoto, waar een grote afzetmarkt was van welvarende kooplieden. Ganryo's werk zal nog eens te meer gewild zijn geweest doordat hij, evenals zijn leermeester Ganku, het mecenaat genoot

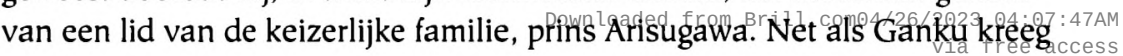




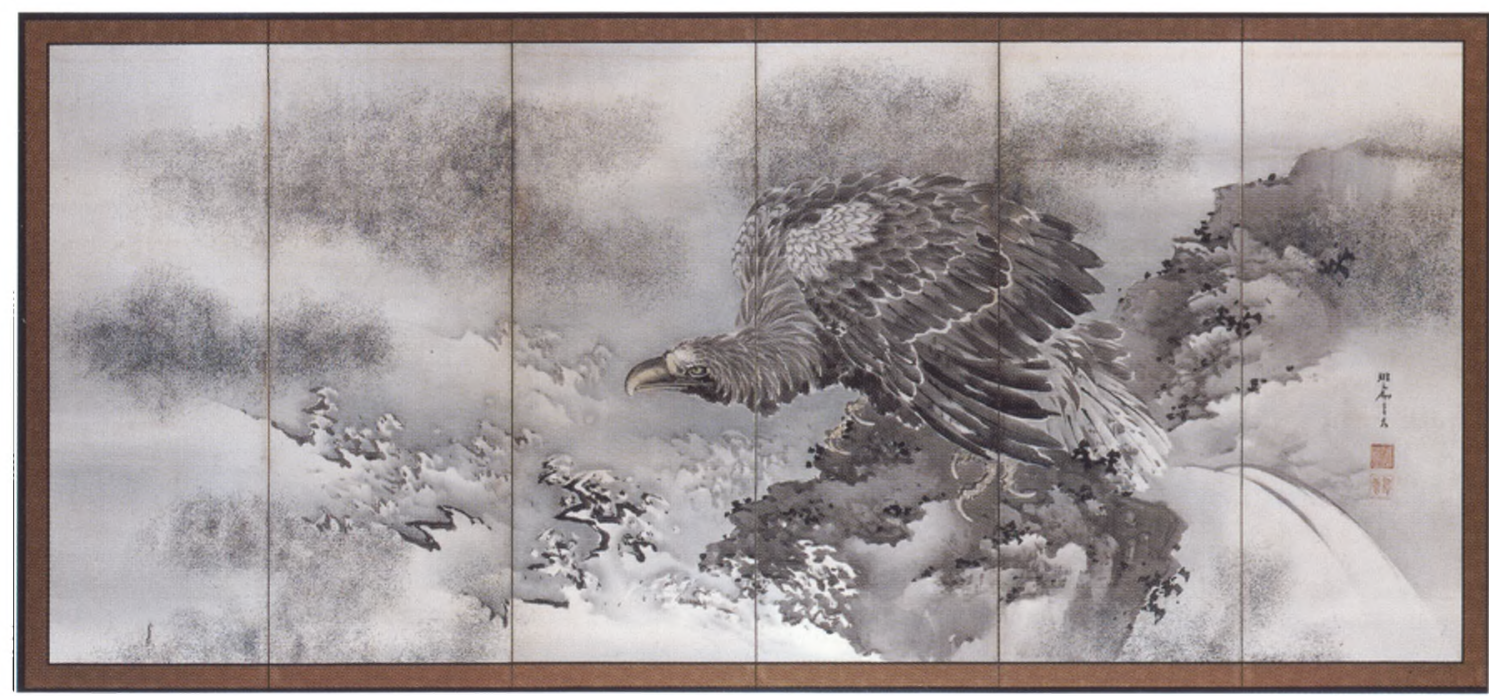

Ganryo van de prins de naam Utanosuke toebedeeld en in de Heian jinbutsushi (Optekening van beroemde personen in Heian [Kyoto]) wordt Ganryo in 1830 voor het eerst onder deze naam vermeld. Het zal rond deze tijd zijn geweest dat hij zijn werk met de naam Utanosuke ging signeren en ook deze twee schermen dragen het Utanosuke-zegel en signatuur. Aangezien een paar schermen met identieke zegels in de collectie van het Musée Guimet gedateerd is als 1832, lijkt het aannemelijk dat deze pas verworven kamerschermen eveneens rond die tijd gemaakt zijn.

\section{Noot}

1. In het vorige nummer staan deze twee wachterfiguren al afgebeeld. Hier afgebeeld is een detail van een van hen (inv.nr. AK-MAK-1717); op het omslag prijkt de ander (inv.nr. AK-MAK-1716). 